\title{
Life History Tactics in Cohorts of a Partial Migratory Brown Trout (Salmo trutta L.) Population
}

\author{
Ivan C. Olsson ${ }^{1,2}$ and Larry A. Greenberg ${ }^{1}$ \\ ${ }^{1}$ Department of Biology, Karlstad University, 65188 Karlstad, Sweden \\ ${ }^{2}$ Department of Environmental Affairs, Aquatic Ecology, County Administrative Board of Scania, 20515 Malmö, Sweden
}

Correspondence should be addressed to Ivan C. Olsson, ivan.olsson@lansstyrelsen.se

Received 22 June 2011; Accepted 11 August 2011

Academic Editor: D. Pimentel

Copyright ( 92011 I. C. Olsson and L. A. Greenberg. This is an open access article distributed under the Creative Commons Attribution License, which permits unrestricted use, distribution, and reproduction in any medium, provided the original work is properly cited.

\begin{abstract}
We monitored temporal changes in body size for three cohorts of a partial migratory, lake-migrating brown trout population. We tested if body mass differed between nonmigratory males, migrants, and other members of the cohort (females and immature males). We hypothesized that large-sized individuals would mature as nonmigratory males or migrate at younger ages than smallsized individuals. As previous studies have shown that female fecundity is influenced by body size and that more trout from the downstream section (D) of the stream migrated than from the upstream section (U), we hypothesized that there would be a greater proportion of mature males in $\mathrm{D}$ than $\mathrm{U}$. We found that body size of males that reproduced was similar to migrants that migrated the subsequent spring and larger than other cohort members. Reproducing males had a larger body size than equal-aged males that delayed reproduction. Similarly, individuals that migrated had a larger body size than equal-aged individuals that migrated subsequently. The proportion of mature males was greater in D than in U. The fact that body size differentiation occurred late in ontogeny and that age of maturation and migration varied within cohorts suggests that the decision to mature or migrate might be conditionally dependent.
\end{abstract}

\section{Introduction}

For salmonids, migration is normally associated with movements between feeding, refuge, and reproductive areas [1]. By exploiting better feeding habitats (i.e., the sea or a lake), migration normally enables individuals to attain high growth rates, size-at-age, and fecundity [2]. There are also drawbacks to migration as the migratory journey itself often is associated with delayed reproduction, high mortality, and energy and time losses $[3,4]$. Females should predominate among migrants [5-8] because high fecundity is more closely associated with large body size in females than in males [911]. Females may also benefit from large body size as they may be more attractive to males and better able to defend and obtain high-quality spawning nests than small-sized females $[12,13]$.

Thorpe's [14] studies of Atlantic salmon suggest that migratory and resident tactics can be viewed as two conflicting developmental processes, where individuals that optimize for residency (i.e., delay or exclude migration) focus their energy on maturation, whereas migrants focus their energy on somatic growth, with the potential of obtaining high payoffs by delaying reproduction. Maturation should be the first priority for all individuals, occurring if a series of genetically determined threshold conditions are met [15]. The thresholds are believed to be based on some combination of an individual's body size, growth rate, and/or energy reserves [15-18]. If the threshold is not exceeded, the individual may either become migratory, or else delay its decision as to whether it should migrate or become sexually mature $[14,15]$.

Several studies have demonstrated that environmental factors can promote residency in migratory populations and migration in resident populations, although the role of genetics cannot be ignored [4, 19-22]. Individual growth rates are believed to be of particular importance [21-24], in part because habitats providing high growth rates normally promote residency, whereas habitats providing low growth rates promote migration, although the opposite relationship 
has also been reported $[2,20]$. It is believed that individuals with high metabolic demands experience stronger food limitations than individuals with low metabolic demands [25]. However, the extent to which this is realized should depend on environmental conditions. For example, Álvares and Nicieza [26] found that survival and growth of brown trout were negatively correlated with metabolic rate in two wild populations, whereas no correlation was detected in two other populations. Thus, a combination of internal (i.e., metabolic rates) and external factors (i.e., growth opportunities) presumably determines individual fate and whether an individual decides to migrate or mature as a nonmigrant.

In partial migratory populations, migration is not undertaken by all individuals, even though all individuals presumably originate from the same gene pool $[19,27]$. Previously, in Greåna River, we studied partial migration in a lake-migrating, brown trout population, whose genetic background is not known, and found that most migrants originated from a downstream section (D: downstream section) in Greåna River, where population density was high and individual growth rates were low. In contrast, few migrants originated from an upstream section $(\mathrm{U}=$ upstream section) in the river, where population density was low and individual growth rates were high [28]. A transplant experiment, in which brown trout from the $\mathrm{D}$ was moved to the $\mathrm{U}$ and vice-versa, showed that the decision to migrate to the lake was influenced by environmental factors as $\mathrm{U}$ individuals exposed to $\mathrm{D}$ conditions decreased their growth rates and increased their migratory tendency, whereas $D$ individuals exposed to $U$ conditions increased their growth rates and decreased their migratory tendency [22].

Because growth rates and body weight might influence whether an individual will become migratory or mature as a nonmigrant $[4,20]$, we tested if body mass differed between future (1) nonmigratory males, (2) migrants (include both males and females), and (3) other members (i.e., females and immature males that never developed any detectable tactic during the study period) from three different cohorts of this landlocked, partial migratory lake-migrating population of brown trout. Within each of the cohorts, we hypothesized that large-sized individuals would mature as nonmigratory males or become migratory at younger ages than small-sized individuals. Furthermore, based on differences in growth and migration rates between the $\mathrm{D}$ and the $\mathrm{U}$, we hypothesized that $\mathrm{U}$ males would mature at a younger age than $\mathrm{D}$ males. Moreover, we hypothesized that the relative proportion of mature males would be greater in D (migratory habitat) than in $U$ (nonmigratory habitat). The high proportion of mature males in $\mathrm{D}$ is predicted because females are believed to be more motivated to migrate to the lake, where growth opportunities are presumed to be good than males, since female fecundity (i.e., number of eggs produced) is more strongly influenced by body size than male fecundity.

\section{Material and Methods}

2.1. Study Site. The study was conducted in Greåna River, which is characterized by two distinct spawning and rearing areas, D (250 m-long, $1335 \mathrm{~m}^{2}$ ) and $\mathrm{U}$ (265 m-long, $950 \mathrm{~m}^{2}$ ), that are geographically separated by a slow-flowing $560 \mathrm{~m}$ long lentic segment (area: $70000 \mathrm{~m}^{2}$ ). Migrants from both D and U migrate downstream to Lake Övre Gla. Detailed information about the study site, the brown trout population and the tagging program is found in Olsson and Greenberg [28].

2.2. The Cohorts. Three cohorts of individually PIT-tagged brown trout (approximately 1200 individuals were tagged) were monitored by sampling the $\mathrm{D}$ and the $\mathrm{U}$ of Greåna River in May (only 2002 and 2003), September, and October each year from 2001 to 2003. By following individual development during this period, we were able to divide the fish into three groups: (1) nonmigratory mature males, (2) migrants and (3) an unspecified nonmigratory group consisting of females and immature males (hereafter referred to as the mixed group). We estimated population density of each age class of brown trout in 2001 and 2002 in the D and the $\mathrm{U}$ by the three-pass electrofishing removal method, conducted in 6-39 m long stream sections $[29,30]$. Age was determined by examining length frequency distributions and through the fact that we followed individually marked fish, of which many were marked during their first year of life. Migrants were identified based on captures in a fish trap that was designed to capture all fish as they exited the mouth of the river. Non-migratory mature males were captured by electrofishing in October and November 2001-2003 and identified by palpating the abdomen to see if milt was released. During the spawning season in 2003, mature males were also identified by analyzing blood plasma 11-ketotestosteron (11-kt) samples for 27 (26 tagged) individuals from the D and 21 (20 tagged) individuals from the U. Blood plasma was sampled from the caudal peduncle using a syringe and then collected in heparinized tubes that were centrifuged so that the plasma content could be drawn off before being stored at $-70^{\circ} \mathrm{C}$. Later, the plasma content of 11-kt was analyzed by radioimmunoassay [31]. The concentration of 11-kt ranged from $0.9-7.3 \mathrm{ng} \mathrm{mL}^{-1}$, where values of $0.9-1.6 \mathrm{ng} \mathrm{mL}^{-1}$ corresponded to females and immature males, and values $>1.6 \mathrm{ng} \mathrm{mL}^{-1} 11$-kt corresponded to mature males, based on previous abdominal palpations of the fish.

Olsson et al. [22] conducted a transplant experiment in Greåna River in 2001 and found that growth rates increased for $\mathrm{D}$ individuals transplanted to the $\mathrm{U}$ during autumn 2001, whereas U individuals transplanted to the D decreased their growth rates. Thus, the 2001 data on body mass for transplanted fish is presumably biased and has therefore been removed (number of body mass readings removed: 689) from the analysis, that is, only data for nontransplanted fish were analyzed. However, the transplantation did not change original densities and the transplantation effect on growth rates was short-termed as growth differences between transplanted and nontransplanted individuals were nonsignificant in subsequent years. Thus, body mass development of transplanted and nontransplanted individuals was analyzed together for each of the cohorts in 2002 and 2003. 
TABLE 1: Summary of Kruskal-Wallis analyses, testing for the effect of tactic on body mass for three separate cohorts (termed Co A, Co B, and Co C) of brown trout monitored from 2001 to 2003 in Greåna River. $N$ is shown for the number of females and immature males (Fe+Im), number that migrated 2002 (Mig 02), 2003 (Mig 03), males maturing in 2001 (Mmale 01), 2002 (Mmale 02), and 2003 (Mmale 03). If total $N<10$, no Kruskal-Wallis test was conducted. A graphic illustration of changes in body mass over time is given in Figure 2.

\begin{tabular}{|c|c|c|c|c|c|c|c|c|c|c|c|c|c|}
\hline \multirow{2}{*}{ No. } & \multirow{2}{*}{ Cohort } & \multirow{2}{*}{ Year } & \multirow{2}{*}{ Month } & \multirow{2}{*}{ Age } & \multicolumn{7}{|c|}{$N$} & \multicolumn{2}{|c|}{ Kruskal-Wallis test } \\
\hline & & & & & $\mathrm{Fe}+\mathrm{Im}$ & Mig 02 & Mig 03 & Mmale 01 & Mmale 02 & Mmale 03 & Total & $X^{2}$ & $P$ \\
\hline 1 & Co A & 2001 & Sep & $0+$ & 534 & 0 & 2 & 0 & 3 & 2 & 541 & 6.9 & 0.080 \\
\hline 2 & Co A & 2001 & Oct & $0+$ & 188 & 0 & 0 & 0 & 5 & 2 & 195 & 9.5 & 0.008 \\
\hline 3 & Co A & 2002 & May & $1+$ & 271 & 0 & 0 & 0 & 8 & 3 & 282 & 1.1 & 0.590 \\
\hline 4 & Co A & 2002 & Sep & $1+$ & 149 & - & 5 & 0 & 8 & 4 & 166 & 21.5 & $<0.001$ \\
\hline 5 & Co A & 2002 & Oct & $1+$ & 147 & - & 4 & 0 & 9 & 6 & 166 & 21.0 & $<0.001$ \\
\hline 6 & Co A & 2003 & May & $2+$ & 27 & - & 5 & 0 & 0 & 1 & 35 & 5.3 & 0.021 \\
\hline 7 & Co A & 2003 & Sep & $2+$ & 39 & - & - & 0 & 0 & 4 & 43 & 9.1 & 0.003 \\
\hline 8 & Co A & 2003 & Oct & $2+$ & 51 & - & - & 0 & 0 & 11 & 62 & 8.0 & 0.005 \\
\hline 1 & Co B & 2001 & Sep & $1+$ & 166 & 6 & 2 & 2 & 3 & 0 & 179 & 14.5 & $<0.006$ \\
\hline 2 & Co B & 2001 & Oct & $1+$ & 102 & 6 & 4 & 2 & 2 & 0 & 116 & 18.2 & 0.001 \\
\hline 3 & Co B & 2002 & May & $2+$ & 100 & 20 & 9 & 0 & 7 & 0 & 136 & 27.2 & $<0.001$ \\
\hline 4 & Co B & 2002 & Sep & $2+$ & 31 & - & 9 & 0 & 8 & 0 & 48 & 7.4 & 0.025 \\
\hline 5 & Co B & 2002 & Oct & $2+$ & 43 & - & 9 & 0 & 9 & 0 & 61 & 12.7 & 0.002 \\
\hline 6 & Co B & 2003 & May & $3+$ & 12 & - & 14 & 2 & 3 & 2 & 33 & 8.3 & 0.011 \\
\hline 7 & Co B & 2003 & Sep & $3+$ & 4 & - & - & 1 & 0 & 1 & 6 & - & - \\
\hline 8 & Co B & 2003 & Oct & $3+$ & 4 & - & - & 0 & 2 & 3 & 9 & - & - \\
\hline 1 & Co C & 2001 & Sep & $2+$ & 41 & 6 & 0 & 5 & 2 & 0 & 54 & 11.4 & 0.010 \\
\hline 2 & Co C & 2001 & Oct & $2+$ & 23 & 12 & 0 & 3 & 1 & 0 & 39 & 9.7 & 0.021 \\
\hline 3 & Co C & 2002 & May & $3+$ & 26 & 23 & 0 & 0 & 4 & 0 & 53 & 22.7 & $<0.001$ \\
\hline 4 & Co C & 2002 & Sep & $3+$ & 16 & - & 0 & 0 & 5 & 0 & 21 & 2.5 & 0.066 \\
\hline 5 & Co C & 2002 & Oct & $3+$ & 15 & - & 0 & 0 & 7 & 0 & 22 & 6.3 & 0.012 \\
\hline 6 & Co C & 2003 & May & $>3+$ & 2 & - & 0 & 0 & 0 & 0 & 2 & - & - \\
\hline 7 & Co C & 2003 & Sep & $>3+$ & 4 & - & 0 & 0 & 0 & 1 & 5 & - & - \\
\hline 8 & Co C & 2003 & Oct & $>3+$ & 3 & - & 0 & 1 & 0 & 0 & 4 & - & - \\
\hline
\end{tabular}

2.3. Analysis. Ideally, we would have wanted to test for differences in individual growth rates between nonmigratory males, migrants, and the unspecified group of nonmigrants. In theory, this should have been possible as PIT-tagging individuals allowed us to follow fish over time. However, such an analysis requires that the same fish be recaptured between successive samplings, which in our case would have reduced sample sizes for nonmigratory males and migrants to levels that precluded statistical testing. Consequently, we tested body mass, and we followed changes in body mass over time as a proxy for growth rates. Because of both low sample sizes for some groups and very large differences in sample sizes between groups, Kruskal-Wallis tests were used to test for differences in body mass (g) between migrants, mature males, and the mixed group for each sampling period separately. Chi-square tests were used to test if the propensity to mature and the age of maturation differed between $\mathrm{D}$ and the $\mathrm{U}$, and if the number of individuals with low $\left(<1.6 \mathrm{ng} \mathrm{mL}^{-1}\right)$ and high $\left(>1.6 \mathrm{ng} \mathrm{mL}^{-1}\right)$ concentrations of 11-kt differed between the D and U habitats in 2003. All statistics were performed using SAS, version 8.2 (SAS Institute, Cary, NC, USA).

\section{Results}

3.1. Descriptive. For 2001 and 2002, the mean densities $\left(100 \mathrm{~m}^{-2} \pm 95 \% \mathrm{CI}\right)$ of brown trout aged $0+$ and $1+$ years were higher in the $\mathrm{D}(43.0 \pm 2.6$ and $14.9 \pm 1.3$, resp. $)$ than in the $\mathrm{U}(34.7 \pm 0.9$ and $11.0 \pm 0.2$, resp. $)$. These between section differences in density were substantial since there was no overlap in the $95 \%$ CI. In contrast, densities of $\geq 2+$ year old brown trout did not differ between sections (D: $3.7 \pm 0.3$ and $\mathrm{U}: 4.1 \pm 0.25$ ).

The proportion of mature males in the river ranged from $2.3-5.7 \%$ for $1+$ brown trout, $8.1-21.6 \%$ for $2+$ brown trout and $46.7-50.0 \%$ for $3+$ brown trout in October 20012003 (Table 1). For migrants, the proportion ranged between $16.2-17.2 \%$ for $2+$ brown trout, and $73.7-76.7 \%$ for $3+$ brown trout in May 2002 and 2003 (Table 1). As we caught all migrants in the trap at the river mouth and approximately $70 \%$ of the population in the river, based on Zippin [29], the nonmigratory fraction is probably underestimated in relation to the migratory fraction for each of the three cohorts. The two different tactics, that is, to migrate or to remain in the river, were not irreversible as three 


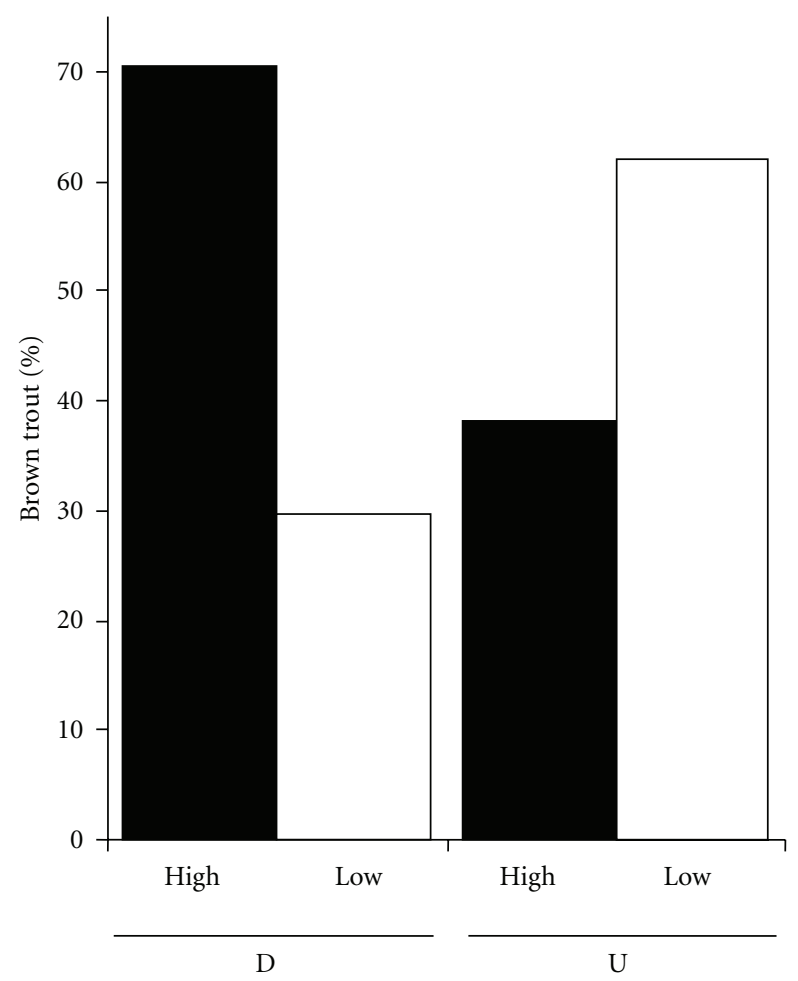

Figure 1: The percentage $(\%)$ of brown trout with low $(<1.6$, white bars) and high ( $>1.6$, black bars) levels of plasma 11ketotestosterone (11-kt) in the downstream section (D) and the upstream section (U) in Greåna River. Low levels of 11-kt corresponded to females and immature males, whereas high levels corresponded to mature males.

mature males (one $1+$ and two $2+$ years old) captured in the river in 2001 and 2002 became migrants the year following spawning. In addition, three male migrants (two $2+$ and one 3+ years old) returned and matured in Greåna River after two to four months in the lake (referred to as "finnocks").

3.2. Maturation. In May of each year, an average of $6 \%$ (range: $4-8 \%$ ) of all brown trout sampled in the river was mature males, and $25-40 \%$ of these males had bite marks on their bodies, presumably originating from spawning activities. The proportion of mature males did not differ between the $\mathrm{U}$ and the $\mathrm{D}$ habitats (aged 1+: $X_{1}^{2}=0.3, P=$ $0.575,2+: X_{1}^{2}=0.05, P=0.820,3+: X_{1}^{2}=0.05, P=$ $0.820)$, nor was there a significant difference in the age of maturation between the $U$ (mean age: 1.9) and the $D$ (mean age: 1.7) habitats, although there was a tendency for $U$ males to mature at a younger age than D males in 2002 and 2003 $\left(X_{2}^{2}=5.2, P=0.074\right.$ and $X_{2}^{2}=4.8, P=0.091,2002$ and 2003 , resp.). The hormone level analysis in 2003 revealed that the relative number of mature males was higher in the $D$ than in the $\mathrm{U}\left(X_{1}^{2}=5.0, P=0.025\right.$, Figure 1$)$.

3.3. Changes in Body Mass over Time. By examining changes in body mass over time, three general patterns emerged. First, for a given age class, individuals belonging to the mixed group had a lower body mass than mature males that would reproduce later in the same year and migrants that would migrate the following spring (Table 1, Figure 2). Second, males maturing during the current year had larger body mass than same-aged males that reproduced in subsequent years. Similarly, body mass of individuals that migrated the following spring had larger body masses in the autumn than same-aged individuals that migrated in subsequent years. Below we illustrate these general patterns for each of the three monitored cohorts.

3.3.1. Cohort A. In October 2001, body mass of $0+$ males that would reproduce at age $1+(2002)$ was larger than for males that would reproduce at age $2+$ (2003) and for individuals belonging to the mixed group (Table 1, Figure 2(a)). The following May, there were no differences in body mass between maturing males, migrants, and the mixed group. In autumn 2002, mature males and individuals that would migrate the following spring (2003) had similar body masses and were larger than individuals in the mixed group. Similarly, in 2003, mature males had a larger body mass than the mixed-group individuals. Spawning in 2003 started sooner than in 2001 and 2002, and the decrease in body mass from September to October (2003) by mature males was probably due to spawning activities.

3.3.2. Cohort B. In autumn 2001, body mass of reproducing males at age $1+(2001)$ and migrants that would migrate the following spring at age $2+(2002)$ was larger than all other groups of brown trout (Table 1, Figure 2(b)). In May 2002, 2+ migrants had a larger body mass than $2+$ males that would reproduce in autumn 2002, as well as future migrants (2003) and individuals belonging to the mixed group. In September 2002, mature males had larger mean body mass than both individuals migrating the subsequent year (2003) and the mixed-group individuals, whereas in October migrants exhibited an accelerated growth so that mature males and migrants had similar mean body masses, and both these groups of fish had larger body masses than individuals from the mixed group. By May 2003, the migrants had larger body mass than the postspawned males $(2+)$, which in turn were larger than the mixed-group individuals. Due to small sample sizes, we did not test for differences among groups in autumn 2003. However, during September and October 2003, three individuals originating from the mixed group decreased in body mass considerably, indicating they might have been females that spawned.

3.3.3. Cohort C. In autumn 2001, individuals migrating the subsequent year (2002) had larger body masses than individuals belonging to the mixed-group (Table 1, Figure 2(c)). By May 2002, migrants of age 3+ had increased their body mass considerably and were larger than $3+$ males that would reproduce in autumn 2002 and 3+ individuals in the mixed group. In September 2002, mature males had significantly larger body masses than the mixed group individuals $(P=$ $0.012)$, but this was not the case in October $(P>0.05)$. No 


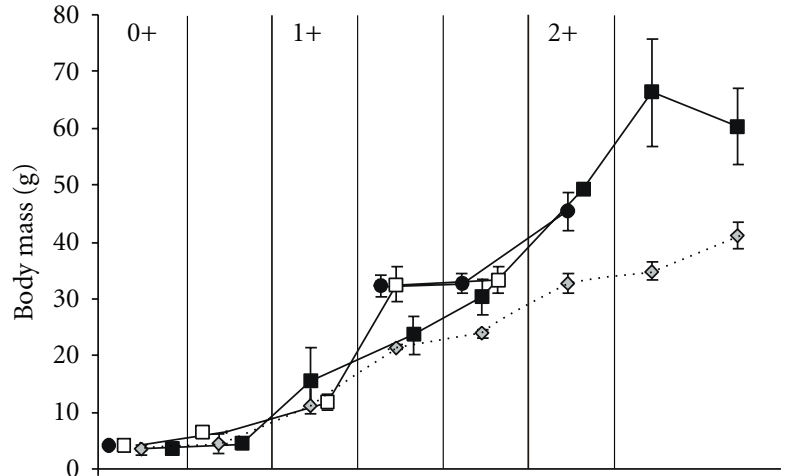

(a)

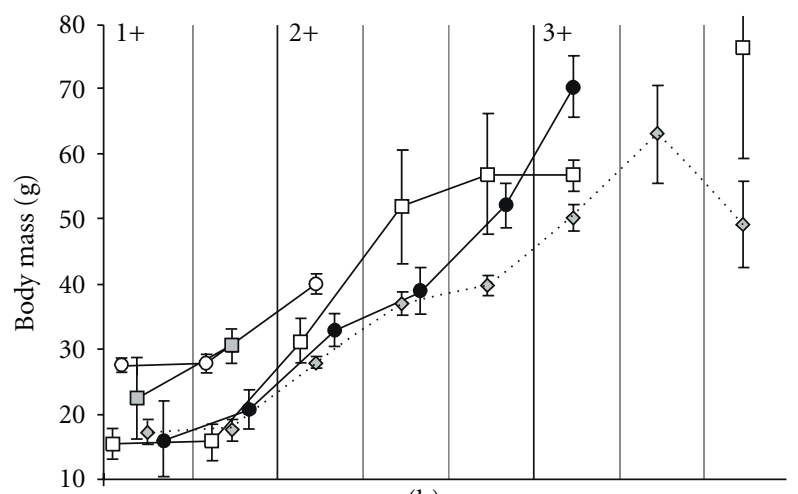

(b)

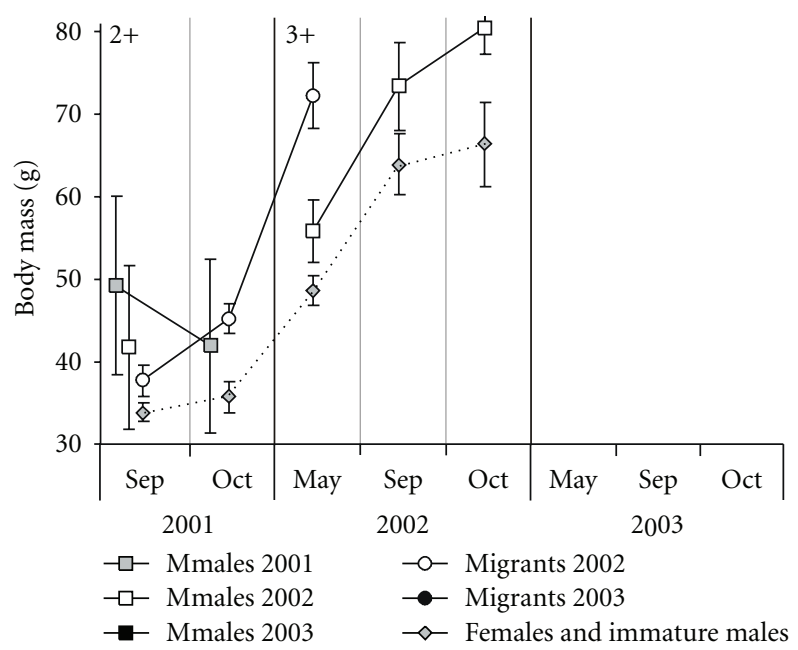

(c)

Figure 2: Changes in body mass over time ( $\mathrm{g} \pm 1 \mathrm{SE}$ ) of different brown trout groups belonging to three different cohorts (Cohort (a), Cohort (b), and Cohort (c)); (1) males maturing in 2001 (Mmales 2001, grey squares), 2002 (Mmales 2002, white squares), and 2003 (Mmales 2003, black squares), (2) individuals migrating in 2002 (Migrants 2002, white circles) and 2003 (Migrants 2003, black circles), and (3) females and immature males (diamonds) in Greåna River from September 2001 to October 2003. Where no SE is shown, the height of the point is >SE. Data points within the sampling months have been moved horizontally to improve readability of the figure. Note that the $Y$-axis differs in scale between the three different panels. See Table 1 for statistics. analysis was conducted on data from 2003 due to low sample sizes.

\section{Discussion}

Variation in life-history tactics within the brown trout population in Greåna River was considerable, with patterns just as complex as shown for many anadromous salmonid populations [4]. Individuals aged $\geq 1+$ developed either migratory or resident tactics, and in a few cases individuals chose both tactics (i.e., mature males became migrants in subsequent years and vice-versa). Interestingly, a relative large fraction of the population never developed any detectable tactic, that is, the mixed group that consisted of females and immature males during the study period (Table 1). In general, the females and immature males had a lower body mass than both migrants and mature males. Presumably, many of these individuals died during the study period. Moreover, some of these individuals were likely to have been mature females, especially in the $\mathrm{U}$, as less than $5 \%$ of the brown trout migrated from this river section. The large loss in weight $(20 \%)$ by 3 individuals belonging to the mixed group in autumn 2003 may reflect the fact that some of these individuals were postspawning females.

As migration rates were higher in the $\mathrm{D}$ than in the $\mathrm{U}$ [28], we predicted that the male to female sex ratio would be higher in the $\mathrm{D}$ than in the U. The hormone analysis supported this prediction as the number of mature males relative to the number of females and immature males was higher in the $\mathrm{D}$ than in the $\mathrm{U}$. This result is consistent with previous studies, where females have been reported to migrate at a higher rate than males, suggesting that females benefit more from migration than males [5, 6, 8-10].

As reported previously in Greåna River [28], migrants increased their body mass dramatically from October to May, presumably due to high consumption rates, particularly in the spring $[25,32]$. Large body mass is associated with a relatively low size-dependent mortality during migration and post-migration $[3,20]$. In contrast, postspawning mature males sampled in May (2003) showed no increase in body mass and had severe bite marks on their body, probably due to high energy expenditures and hazardous activities involved in spawning as sneakers [4]. The fact that only a few males were recaptured during postspawning conditions may also indicate that mortality rates were high during spawning [33]. Another possible explanation as to why so few mature males were recaptured could be that they migrated to the lake. This "mix" of tactics is typical for salmon but has rarely been reported for brown trout $[5,6,23]$. In Greåna River, however, migration does not appear to be responsible for the low recapture rates since only three postspawning males became migratory, based on captures in the fish trap.

As numerous studies have shown that it is mainly largesized and fast-growing individuals that mature as resident males and at a young age $[32,33]$, we predicted that nonmigratory males would mature at younger age in the $U$ where growth rates were higher than in the $D$, where growth rates were low. However, we did not find statistical support for this hypothesis, given that there was a tendency 
for mature males to be younger in the $U$ than in the D in 2002 and 2003 ( $P=0.074$ and 0.091 , for respective years $)$, but this may reflect small sample sizes for mature males.

For both hatchery-reared salmon and wild populations of brown trout and brook trout, it has been reported or proposed that individuals with high metabolic rates and feeding motivation often grow fast and develop migratory behavior as they become growth-limited, which contrasts with the situation for slow-growing, nonmigratory individuals with low metabolic rates and feeding motivation [23, 25, 3437]. Our results corroborate these earlier findings in so far as the migrants had a larger body mass than females and immature males. However, we were unable to distinguish between migratory individuals and mature males based on size. In the literature, the evidence is equivocal as to whether fast-growers migrate or mature as residents [20]. Thorpe [14] hypothesized that a salmon's first priority should be to mature as soon as possible and that migration should only take place if energy resources are insufficient for maturation. Furthermore, Thorpe et al. [15] suggested that individuals have several windows of opportunity to decide whether to mature or to migrate, the first one is approximately one year before spawning in autumn and the second the following spring. At each of these "windows," the individual evaluates whether or not its energy reserves exceed a certain threshold level. If the thresholds are not met, maturation will not take place, instead the individual is believed to prepare itself for migration, but only if an additional threshold is exceeded. The thresholds are believed to be genetically determined and influenced by both "internal factors," such as metabolic costs and feeding intensity and "external factors", such as feeding opportunities and competition.

We hypothesize that brown trout that elects to mature meets the necessary energetic requirements for maturation, whereas other individuals, albeit of similar size, elect to migrate, presumably due to higher metabolic requirements than the maturing resident males [38]. The facts that there was a large variation in the age of maturation and migration and that the decision to mature as a resident or become migratory is taken relatively late in ontogeny are consistent with the notion that both the resident and the migratory tactics might be influenced by environmental factors [22], even though the role of heritability has not been evaluated in this system. This is probably because growth and survival vary with body size (age) and between habitats [20]. Moreover, individuals within the same population might vary in their metabolic requirements, which should also lead to differences in the age at which individuals decide to mature as residents or migrate [39]. This high level of variation in different attributes, in combination with the work by Wysujack et al. [40] and Olsson et al. [22], who found that the proportion of migrants varied in response to changing food availability, suggests that the decision to mature as a resident or become migratory is conditionally dependent.

\section{Acknowledgments}

The authors thank the field workers, especially M. Magnusson, M. Olofsson, J. Witwiky, R.-K. Ratilainen, P. Gustavsson,
J. Karlsson, K. Wysujack, C. Hollenstein, and O. Gustavsson, including the people living in the Glaskogen Nature Reserve, for their permission to work in their streams, in particular M. and A. Gustavsson. The National Board of Forestry, the MiljöFocus group, Carl Tryggers Stiftelse, and the Department of Biology supported this study financially. Erik Degerman gave them helpful comments on earlier versions of the paper.

\section{References}

[1] T. G. Northcote, "Juvenile current response, growth and maturity of above and below waterfall stocks of rainbow trout, Salmo gairdneri," Journal of Fish Biology, vol. 18, no. 6, pp. 741751, 1981.

[2] A. P. Hendry and S. C. Stearns, Evolution Illuminated: Salmon and Their Relatives, Oxford University Press, New York, NY, USA, 2004.

[3] T. Bohlin, J. Pettersson, and E. Degerman, "Population density of migratory and resident brown trout (Salmo trutta) in relation to altitude: evidence for a migration cost," Journal of Animal Ecology, vol. 70, no. 1, pp. 112-121, 2001.

[4] A. Klemetsen, P. A. Amundsen, J. B. Dempson et al., "Atlantic salmon Salmo salar L., brown trout Salmo trutta L. and Arctic charr Salvelinus alpinus (L.): a review of aspects of their life histories," Ecology of Freshwater Fish, vol. 12, no. 1, pp. 1-59, 2003.

[5] B. Jonsson, "Life history patterns of freshwater resident and sea-run migrant brown trout in Norway," Transactions of the American Fisheries Society, vol. 114, pp. 182-194, 1985.

[6] C. Dellefors and U. Faremo, "Early sexual maturation in males of wild sea trout, Salmo trutta L., inhibits smoltification," Journal of Fish Biology, vol. 33, no. 5, pp. 741-749, 1988.

[7] J. M. Elliot, Quantitative Ecology and the Brown Trout, Oxford University Press, New York, NY, USA, 1994.

[8] T. G. Northcote, "Migration and residency in stream salmonids-some ecological considerations and evolutionary consequences," Nordic Journal of Freshwater Research, vol. 67, pp. 5-17, 1992.

[9] B. Jonsson and O. T. Sandlund, "Environmental factors and life histories of isolated river stocks of brown trout (Salmo trutta m. fario) in Søre Osa river system, Norway," Environmental Biology of Fishes, vol. 4, no. 1, pp. 43-54, 1979.

[10] J. L. Baglinière, G. Maisse, P. Y. Lebail, and A. Nihouarn, "Population dynamics of brown trout, Salmo trutta L., in a tributary in Brittany (France): spawning and juveniles," Journal of Fish Biology, vol. 34, no. 1, pp. 97-110, 1989.

[11] K. Morita and Y. Takashima, "Effect of female size on fecundity and egg size in white-spotted charr: comparison between searun and resident forms," Journal of Fish Biology, vol. 53, no. 5, pp. 1140-1142, 1998.

[12] E. P. Van Den Berghe and M. R. Cross, "Natural selection resulting from female breeding competition in a Pacific salmon (coho: Oncorhynchus kisutch)," Evolution, vol. 43, no. 1, pp. 125-140, 1989.

[13] L. B. Holtby and M. C. Healey, "Sex-specific life history tactics and risk-taking in coho salmon," Ecology, vol. 71, no. 2, pp. 678-690, 1990.

[14] J. E. Thorpe, "An alternative view of smolting in salmonids," Aquaculture, vol. 121, no. 1-3, pp. 105-113, 1994.

[15] J. E. Thorpe, M. Mangel, N. B. Metcalfe, and F. A. Huntingford, "Modelling the proximate basis of salmonid life-history 
variation, with application to Atlantic salmon, Salmo salar L," Evolutionary Ecology, vol. 12, no. 5, pp. 581-599, 1998.

[16] D. K. Rowe, J. E. Thorpe, and A. M. Shanks, "Role of fat stores in the maturation of male Atlantic salmon (Salmo salar) parr," Canadian Journal of Fisheries and Aquatic Sciences, vol. 48, no. 3, pp. 405-413, 1991.

[17] I. Berglund, "Growth and early sexual-maturation in baltic salmon (Salmo salar) parr," Canadian Journal of Zoology, vol. 70, pp. 205-211, 1992.

[18] T. Bohlin, C. Dellefors, and U. Faremo, "Probability of first sexual maturation of male parr in wild sea-run brown trout (Salmo trutta) depends on condition factor $1 \mathrm{yr}$ in advance," Canadian Journal of Fisheries and Aquatic Sciences, vol. 51, no. 9, pp. 1920-1926, 1994.

[19] K. Hindar, B. Jonsson, N. Ryman, and G. Stahl, "Genetic relationships among landlocked, resident, and anadromous brown trout, Salmo trutta L.," Heredity, vol. 66, pp. 83-91, 1991.

[20] B. Jonsson and N. Jonsson, "Partial migration: niche shift versus sexual maturation in fishes," Reviews in Fish Biology and Fisheries, vol. 3, no. 4, pp. 348-365, 1993.

[21] K. Morita, S. Yamamoto, and N. Hoshino, "Extreme life history change of white-spotted char (Salvelinus ieucomaenis) after damming," Canadian Journal of Fisheries and Aquatic Sciences, vol. 57, no. 6, pp. 1300-1306, 2000.

[22] I. C. Olsson, L. A. Greenberg, E. Bergman, and K. Wysujack, "Environmentally induced migration: the importance of food," Ecology Letters, vol. 9, no. 6, pp. 645-651, 2006.

[23] J. Cucherousset, D. Ombredane, K. Charles, F. Marchand, and J. L. Baglinière, "A continuum of life history tactics in a brown trout (Salmo trutta) population," Canadian Journal of Fisheries and Aquatic Sciences, vol. 62, no. 7, pp. 1600-1610, 2005.

[24] G. B. Zydlewski, J. Zydlewski, and J. Johnson, "Patterns of migration and residency in coastal cutthroat trout Oncorhynchus clarkii clarkii from two tributaries of the lower Columbia River," Journal of Fish Biology, vol. 75, no. 1, pp. 203-222, 2009.

[25] N. B. Metcalfe, F. A. Huntingford, and J. E. Thorpe, "Feeding intensity, growth rates, and the establishment of life- history patterns in juvenile Atlantic salmon Salmo salar," Journal of Animal Ecology, vol. 57, no. 2, pp. 463-474, 1988.

[26] D. Álvarez and A. G. Nicieza, "Is metabolic rate a reliable predictor of growth and survival of brown trout (Salmo trutta) in the wild?" Canadian Journal of Fisheries and Aquatic Sciences, vol. 62, no. 3, pp. 643-649, 2005.

[27] H. Nordeng, "Solution to the "char problem" based on Arctic char (Salvelinus alpinus) in Norway," Canadian Journal of Fisheries and Aquatic Sciences, vol. 40, no. 9, pp. 1372-1387, 1983.

[28] I. C. Olsson and L. A. Greenberg, "Partial migration in a landlocked brown trout population," Journal of Fish Biology, vol. 65, no. 1, pp. 106-121, 2004.

[29] C. Zippin, "The removal method for population estimation," Journal of Wildlife Management, vol. 22, pp. 82-90, 1958.

[30] T. Bohlin, S. Hamrin, T. G. Heggberget, G. Rasmussen, and S. J. Saltveit, "Electrofishing - theory and practice with special emphasis on salmonids," Hydrobiologia, vol. 173, no. 1, pp. 9 43, 1989.

[31] I. Mayer, H. Lundqvist, B. Berglund, M. Schmitz, R. Schultz, and B. Borg, "Seasonal endocrine changes in Baltic salmon, Salmo salar, immature parr and mature male parr. I. Plasma levels of five androgens, 17-hydroxy-20-dihydroprogesterone and of 17-estradiol," vol. 68, pp. 1360-1365, 1990.
[32] B. H. Letcher and G. Gries, "Effects of life history variation on size and growth in stream-dwelling Atlantic salmon," Journal of Fish Biology, vol. 62, no. 1, pp. 97-114, 2003.

[33] L. Österdahl, "The smolt run of a small Swedish river," in Salmon and Trout in Streams, T. G. Northcote, Ed., pp. 205215, University of British Columbia, Vancouver, Canda, 1969.

[34] N. B. Metcalfe, F. A. Huntingford, and J. E. Thorpe, "Seasonal changes in feeding motivation of juvenile Atlantic salmon (Salmo salar)," Canadian Journal of Zoology, vol. 64, pp. 24392446, 1986.

[35] T. Forseth, T. F. Næsje, B. Jonsson, and K. Hårsaker, "Juvenile migration in brown trout: a consequence of energetic state," Journal of Animal Ecology, vol. 68, no. 4, pp. 783-793, 1999.

[36] G. R. Morinville and J. B. Rasmussen, "Early juvenile bioenergetic differences between anadromous and resident brook trout (Salvelinus fontinalis)," Canadian Journal of Fisheries and Aquatic Sciences, vol. 60, no. 4, pp. 401-410, 2003.

[37] V. Thériault and J. J. Dodson, "Body size and the adoption of a migratory tactic in brook charr," Journal of Fish Biology, vol. 63, no. 5, pp. 1144-1159, 2003.

[38] L. Lans, L. Greenberg, J. Karlsson, O. Calles, M. Schmitz, and E. Bergman, "The effects of ration size on hatcheryraised Atlantic salmon (Salmo salar) and brown trout (Salmo trutta)," Ecology of Freshwater, vol. 20, no. 4, pp. 548-557, 2011.

[39] F. Økland, B. Jonsson, A. J. Jensen, and L. P. Hansen, "Is there a threshold size regulating seaward migration of brown trout and Atlantic salmon?" Journal of Fish Biology, vol. 42, no. 4, pp. 541-550, 1993.

[40] K. Wysujack, L. A. Greenberg, E. Bergman, and I. C. Olsson, "The role of the environment in partial migration: food availability affects the adoption of a migratory tactic in brown trout Salmo trutta," Ecology of Freshwater Fish, vol. 18, no. 1, pp. 52-59, 2009. 

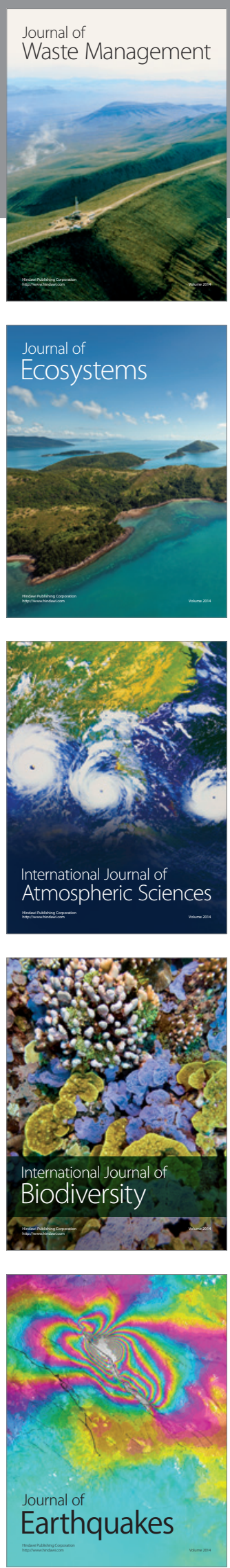
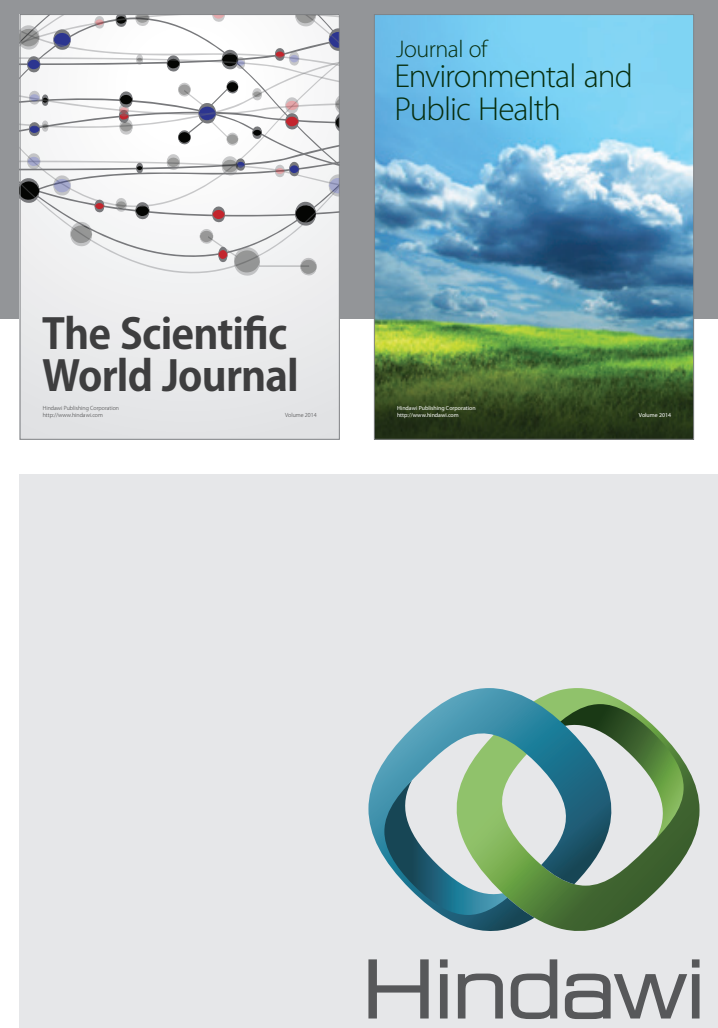

Submit your manuscripts at

http://www.hindawi.com
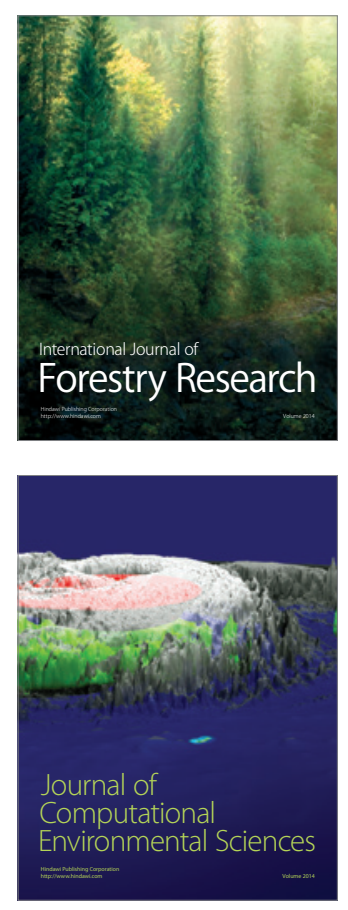
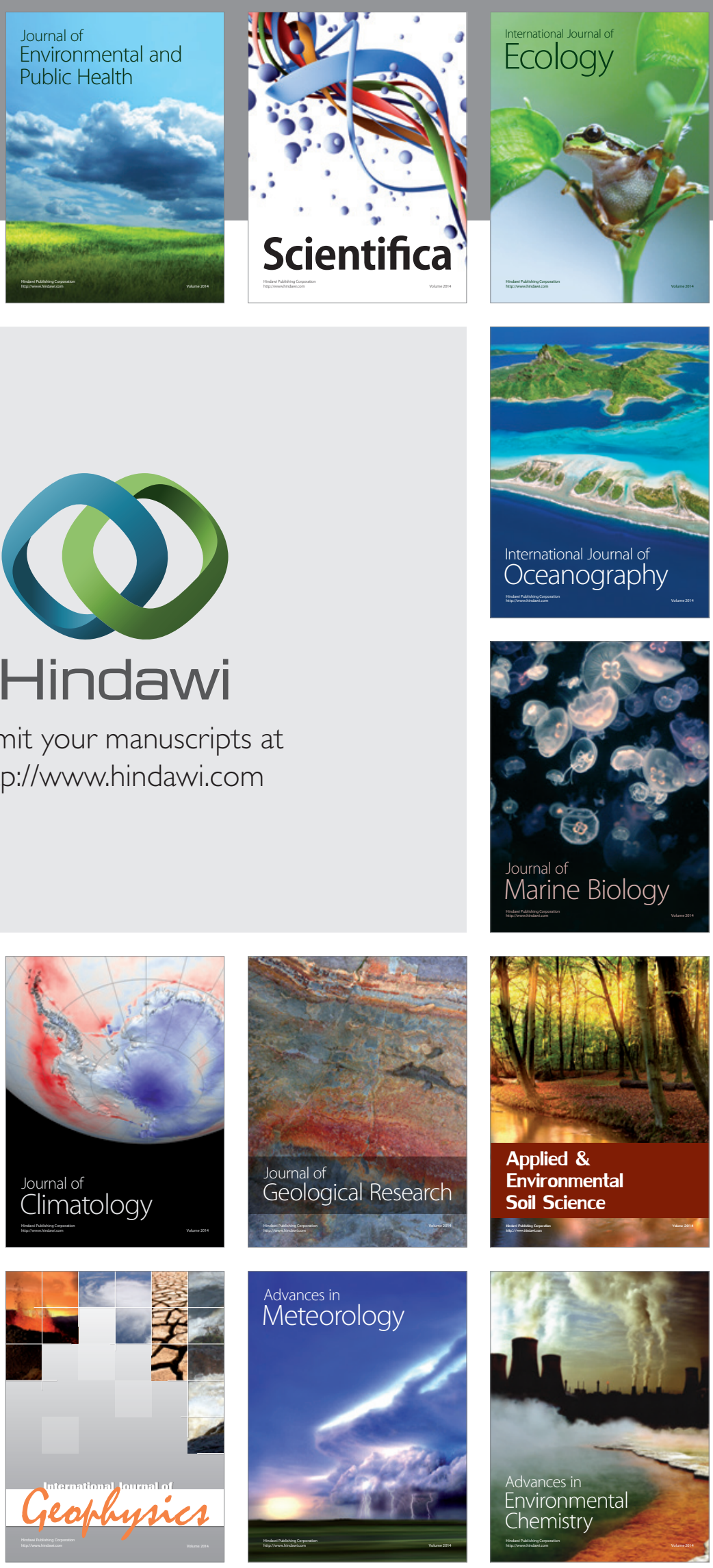